\title{
Calcium Release-Dependent Actin Flow in the Leading Process Mediates Axophilic Migration
}

\author{
B. Ian Hutchins, ${ }^{1,2}$ Ulrike Klenke, ${ }^{1}$ and Susan Wray ${ }^{1}$ \\ ${ }^{1}$ Cellular and Developmental Neurobiology Section, National Institute of Neurological Disorders and Stroke, National Institutes of Health, Bethesda, \\ Maryland 20892-9525, and 2Postdoctoral Research Associate Program, National Institute of General Medical Sciences, National Institutes of Health, \\ Bethesda, Maryland 20892-6200
}

\begin{abstract}
Proper assembly of neural circuits requires newly born neurons to migrate from their place of origin to their final location. Little is known about the mechanisms of axophilic neuronal migration, whereby neurons travel along axon pathways to navigate to their destinations. Gonadotropin-releasing hormone ( $\mathrm{GnRH}$ )-expressing neurons migrate along olfactory axons from the nose into the forebrain during development, and were used as a model of axophilic migration. After migrating, GnRH neurons are located in the hypothalamus and are essential for puberty and maintenance of reproductive function. To gain a better understanding of the mechanisms underlying axophilic migration, we investigated in mice the regulation of movement from calcium signals to cytoskeletal dynamics. Live imaging revealed robust calcium activity during axophilic migration, and calcium release through IP3 receptors was found to stimulate migration. This occurred through a signaling pathway involving the calcium sensor calcium/calmodulin protein kinase kinase, AMP-activated kinase, and RhoA/ROCK. By imaging GnRH neurons expressing actin-GFP or Lifeact-RFP, calcium release was found to stimulate leading process actin flow away from the cell body. In contrast, actin contractions at the cell rear were unaffected by this calcium signaling pathway. These findings are the first to test the regulation of cytoskeletal dynamics in axophilic migration, and reveal mechanisms of movement that have broad implications for the migration of other CNS populations.
\end{abstract}

\section{Introduction}

In the brain, migratory neurons are classified as radial (along radial glia processes), tangential (orthogonal to radial glia fibers), or axophilic (along axons). This classification is functional as well as anatomical since modes of motility may differ. Tangentially migrating cortical interneurons iteratively extend and retract branches (Martini et al., 2009) while radially migrating cortical neurons use somal translocation to rapidly move the nucleus to the distal leading process (Nadarajah et al., 2001). Some neurons, such as cerebellar granule neurons (CGNs), switch between radial and tangential modes of migration (Komuro et al., 2001), suggesting that movement strategies can be selectively engaged. Although neurons migrating along the anteroposterior axis commonly use axophilic mechanisms (Ono et al., 2004; Mapp et al., 2010; Wray, 2010), the underlying mechanisms are not well understood.

Calcium signaling regulates neuronal migration (Komuro and Kumada, 2005; Bortone and Polleux, 2009; Fahrion et al.,

Received Aug. 3, 2012; revised Feb. 20, 2013; accepted Feb. $26,2013$.

Author contributions: B.I.H. and S.W. designed research; B.I.H. and U.K. performed research; B.I.H. analyzed data; B.I.H. and S.W. wrote the paper.

This work was supported by the Intramural Research Program of National Institute of Neurological Disorders and Stroke, National Institutes of Health (NIH) (Grant ZIA NS002824-21 to S.W.), and a postdoctoral fellowship from the Postdoctoral Research Associate Program of National Institute of General Medical Sciences, NIH (B.I.H.). We thank Drs. M. Sixt and R. Wedlich-Söldner for generously providing the Lifeact-RFP mice used in this study.

Correspondence should be addressed to Dr. Susan Wray, 35 Convent Drive, Building 35, Room 3A1212, Bethesda, MD 20892. E-mail:wrays@ninds.nih.gov.

DOI:10.1523/JNEUROSCI.3758-12.2013

Copyright $\odot 2013$ the authors $\quad 0270-6474 / 13 / 3311361-11 \$ 15.00 / 0$
2012), and can be generated by extracellular cues (Guan et al., 2007) and/or genetic programming (Cancedda et al., 2007; Bortone and Polleux, 2009; Bando et al., 2012). In most neurons, relative changes rather than absolute frequencies of calcium transients modulate migration (Bortone and Polleux, 2009; Martini and Valdeolmillos, 2010). Many types of calcium channels contribute to bulk calcium levels, only some of which regulate migration. Signaling specificity is achieved by different calcium sensing proteins associated with calcium channel microdomains (Augustine et al., 2003). Although simple linear models between calcium dynamics and migration rates are unavailable (Moya and Valdeolmillos, 2004; Martini and Valdeolmillos, 2010), genetic and pharmacological manipulations coupled with measurements of relative calcium changes have advanced our understanding of these relationships (Bortone and Polleux, 2009; Martini and Valdeolmillos, 2010).

Transduction of calcium signals into cytoskeletal dynamics that advance the nucleus (nucleokinesis) are unclear. Recently, several mechanisms have been proposed in which cytoskeletal dynamics drive migrating neurons forward. In dissociated CGNs, actin contraction or flow in the leading process was reported to pull the centrosome and cell body forward (Solecki et al., 2009; He et al., 2010). Actin-associated motor protein myosin II is also required for centrosome movement in radially migrating cortical neurons (Tsai et al., 2007). However, actinomyosin dynamics at the cell rear during tangential migration were proposed to retract the trailing process and push the nucleus forward (Bellion et al., 2005; Schaar and McConnell, 2005); later work suggested these dynamics were the primary force driving tangential migration 
(Martini and Valdeolmillos, 2010). The dynamics engaged during axophilic migration are unclear.

Gonadotropin-releasing hormone-1 $(\mathrm{GnRH})$ neurons were used as a model for axophilic migration in this study. Postnatally, GnRH neurons are essential for puberty and reproductive function (Wray, 2002). GnRH cells are well conserved among vertebrates and undergo axophilic migration from the nasal placode into the forebrain in all species examined to date. Here, we found axophilic migration involves a combination of IP3 (inositol triphosphate)-receptor and AMP-dependent kinase (AMPK)-dependent leading process actin translocation and IP3-receptor independent actin contraction at the cell rear, bridging the gap between modes of migration observed in tangential and radial migration.

\section{Materials and Methods}

Nasal explants. All procedures were approved by National Institute of Neurological Disorders and Stroke Animal Care and Use Committee and performed according to National Institutes of Health guidelines. Explants were generated from embryonic day $11.5 \mathrm{em}-$ bryos of either gender as previously described (Klenke and Taylor-Burds, 2012). Both bilateral and unilateral pits were generated (Kramer and Wray, 2000; Casoni et al., 2012). Explants were incubated at $37^{\circ} \mathrm{C}$ in defined serum-free medium in $5 \% \mathrm{CO}_{2}$.

Calcium imaging. Explants were loaded with $0.83 \mu \mathrm{M}$ Calcium Green-1 (Invitrogen), washed, and exposed to imaging conditions on the microscope for $20 \mathrm{~min}$ to acclimate. Imaging was performed at $37^{\circ} \mathrm{C}$ and $5 \%$ $\mathrm{CO}_{2}$. Images were acquired at $10 \mathrm{~s}$ intervals for control and treatment periods, each lasting up to $40 \mathrm{~min}$. Calcium activity was measured as previously described (Klenke and Taylor-Burds, 2012). Briefly, transients were defined as a local maximum over a rolling 15 -frame median baseline that was at least both $1 \mathrm{SD}$ and $12 \%$ over baseline. For comparing calcium activity to migration rate, movement was calculated from the soma center every $2 \mathrm{~min}$. Explants were used at 3-4 d in vitro (DIV), a time when GnRH cells are actively migrating along axons (Casoni et al., 2012). For analysis of sustained calcium response, the mean fluorescence of the $\mathrm{GnRH}$ neurons in each group $(F)$ was normalized to the average fluorescence of the final $5 \mathrm{~min}$ of the control period for that group $(F 0)$. One-way ANOVA was performed on the immediate response $(F / F 0)$ after treatment; graphs of calcium traces show mean $F / F 0 \pm$ SEM.

Confocal microscopy. Images were acquired using a Nikon TE200 microscope with a CSU10 spinning disk confocal (Yokogawa) and Hamumatsu ImagEM C9100-13 EMCCD camera (Hamumatsu) or Retiga SRV (Qimaging) with a $20 \times$ ELWD (extra-long working distance) or a $60 \times$ water-immersion objective (Nikon).

Pharmacology. The following reagents were used: $75 \mu \mathrm{M} 2-\mathrm{APB}$ (Tocris Bioscience), $3 \mu \mathrm{M}$ SKF-96365 (Tocris Bioscience), $100 \mu \mathrm{M}$ flufenamic acid (Sigma-Aldrich), $25 \mu \mathrm{M}$ m-3M3FBS (Tocris Bioscience), $2.5 \mu \mathrm{M}$ U73122 (Enzo Life Sciences), $200 \mathrm{~nm}$ autocamtide-2-related inhibitory peptide (Tocris Bioscience), $20 \mu \mathrm{M}$ STO-609 (Tocris Bioscience), $5 \mu \mathrm{M}$ Compound C (Tocris Bioscience), $500 \mu \mathrm{M}$ 5-aminoinidazole-4carboxamide ribonucleoside (AICAR; Tocris Bioscience), $10 \mu \mathrm{M}$ Y27632 (Tocris Bioscience), $2 \mu \mathrm{M}$ M18 (Tocris Bioscience), $10 \mu \mathrm{g} / \mathrm{ml}$ of concanavalin A (Vector Laboratories).

Migration assays and immunostaining. For chronic pharmacological treatments, reagents were applied from 3 DIV, after olfactory axons have extended and as GnRH neurons begin to emerge, to 6 DIV, when most
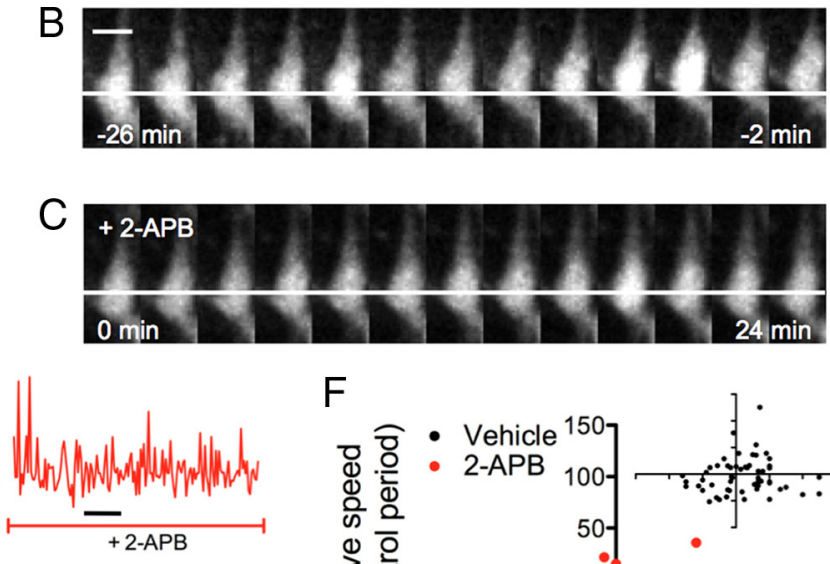

$\mathrm{F}$

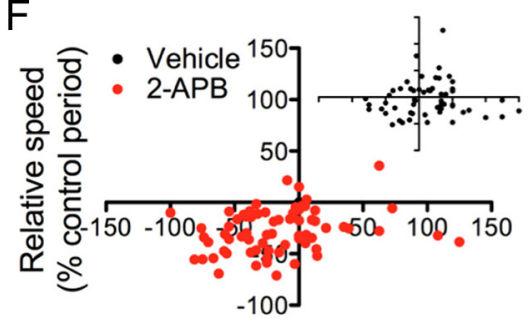

Relative frequency

(\% control period)

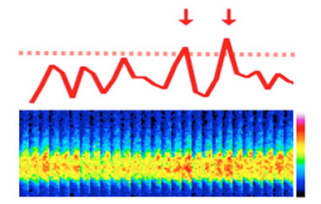

.

Figure 1. Calcium release through IP3 receptors promotes axophilic migration. $\boldsymbol{A}-\boldsymbol{E}$, Single GnRH neuron before and after IP3 receptors with 2-APB. A, Differential interference contrast image (left) and DAB staining for $G n R H$ (right). $\boldsymbol{B}$, Example cence from the same time period. Pseudocolor scale bar, right. $\boldsymbol{F}$, Scatter plot of the change, after adding 2-APB, of the frequencies of calcium transients versus migration rates relative to pretreatment control period ( $p<0.05$, linear regression, $n=68$ cells, $N=$ no relationship (inset). Scale bars, $10 \mu \mathrm{m}$

GnRH neurons cease migrating. Explants were fixed and immunostained for GnRH with DAB as previously described (Klenke and Taylor-Burds, 2012). In olfactory axon assays, olfactory axons were immunostained for peripherin with $\mathrm{DAB}$ while GnRH neurons were immunolabeled with SG staining. Images of olfactory axons in Figure $2 F, G$ were high-pass filtered to correct for uneven illumination. Migration was assessed as the distance of GnRH neurons from the tip of the nasal cartilage or, in unilateral explants, as the distance from the centroid of the pit. During acute migration assays, explants were imaged every minute for $1 \mathrm{~h}$ control and treatment periods. Neuronal migration speed was calculated from each cell's displacement from its original position.

Actin imaging. Explants were prepared from transgenic mice expressing actin-GFP (Fischer et al., 2000) or Lifeact-RFP (Riedl et al., 2010). Six-micrometer $z$-stacks were acquired every $30 \mathrm{~s}$. Images were sharpened with a $5 \times 1$ bandpass filter (ImageJ, National Institutes of Health). Actin was manually tracked. This method was validated with crosscorrelation measurement of raw actin images from the same cells (TRACKER ImageJ plugin, Olivier Cardoso, Paris Diderot University; set to $9 \times 9$ pixel regions and 3 pixel correlation size). Nucleus centroids were tracked to calculate migration rates. To ensure that actin and nuclear movement occurred at the same time, movies were segmented into 2 min frames and movement compared within those frames.

Statistics. Statistics were performed in Prism 5 (GraphPad). Unless otherwise noted, $n$ is the number of cells and $N$ is the number of explants. Two-way ANOVA was used to compare cumulative frequency distributions of chronic treatment groups. Acute migration assays were analyzed by paired $t$ test unless otherwise noted. Model II linear regression was used to analyze cytoskeletal dynamics to account for measurement error in both the dependent and independent axes. This total least-squares regression minimizes the sum of squared distances from the points to the regression line.

Residuals analysis is performed to examine the contribution of a second parameter on a measured variable. This analysis was used to determine whether rear actin contraction contributed, though to a much lesser extent, to migration rate. For this analysis, the residuals of the regression (vertical distances from each data point to the regression line) 

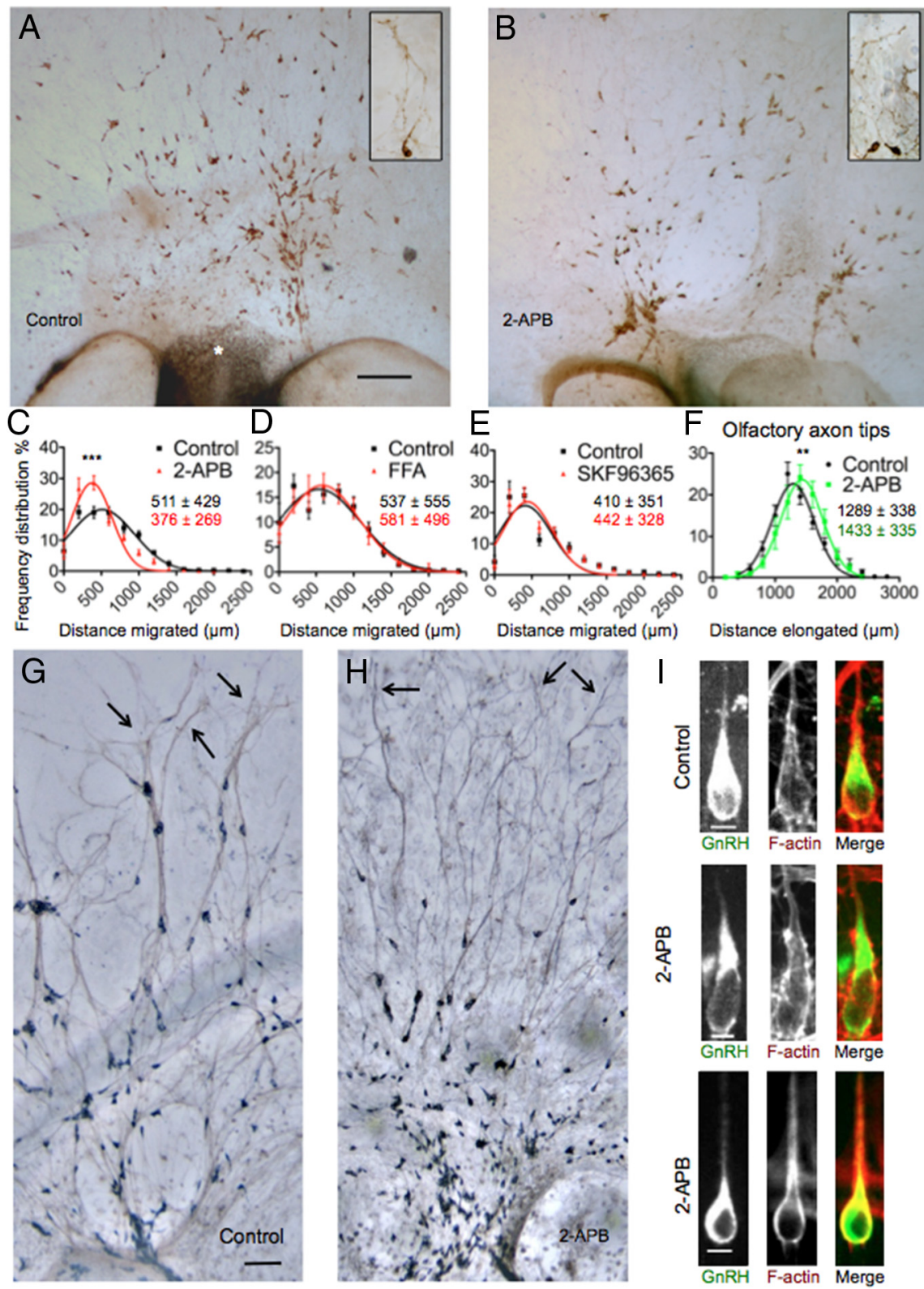

Figure 2. Calcium release through IP3 receptors but not TRP channels promotes long-distance axophilic migration. $\boldsymbol{A}, \boldsymbol{B}$ Example of GnRH neurons (stained brown) in nasal explants. $A$, GnRH neurons migrated from the main tissue mass in control experiments. Asterisk, tip of nasal cartilage. Scale bar, $100 \mu \mathrm{m}$. $\boldsymbol{B}$, GnRH neurons clustered near the main tissue mass in the presence of 2-APB. Insets, Magnified images of GnRH neurons and leading processes. $C-E$, Quantifications of chronic treatment migration assays. Frequency distributions and best-fit Gaussian distribution curves (fitted mean $\pm S D$ in micrometers shown on chart) of distances $\mathrm{GnRH}$ neurons migrated in vehicle control versus 2-APB (C, ${ }^{* * *} p<0.001,2$-way ANOVA, $N \geq 10$ explants), flufenamic acid (FFA) $(\boldsymbol{D}, p>0.05, N=8)$, and SKF96365 $(\boldsymbol{E}, p>0.05, N=7)$. $\boldsymbol{F}$, Frequency distribution of the elongation distances of olfactory axons from the tip of the nasal cartilage. Blocking IP3 receptors slightly increased olfactory axon elongation $\left({ }^{* *} p<0.01\right.$, 2-way ANOVA, $N=8$ ). $\mathbf{G}, \boldsymbol{H}$, Explants stained for peripherin (brown) to label olfactory axons (arrows) and GnRH (dark blue). $\mathbf{G}$, Olfactory axons extended and GnRH neurons migrated throughout the periphery of the explant. Scale bar, $100 \mu \mathrm{m} . \boldsymbol{H}$, Olfactory axons showed robust growth and GnRH neurons remained near the main tissue mass during 2-APB treatment. $I$, Examples of GnRH neurons labeled with GnRH immunofluorescence and phalloidin, treated with vehicle or 2-APB for $24 \mathrm{~h}$. Actin organization appears similar in each example. Scale bar, $5 \mu \mathrm{m}$.

comparing actin versus soma speeds within 2 min time frames were saved. These residual soma speeds were compared with the original actin time-lapse recordings and manually scored for having or not having active rear actin contractions during the $2 \mathrm{~min}$ frame represented by that data point. The contracting/not contracting residual speeds were pooled separately and tested for additional contribution to speed with a onesample $t$ test.

\section{Results}

Since calcium activity is required for axophilic migration (Toba et al., 2005), calcium transients were imaged in migrating $\mathrm{GnRH}$ neurons. Robust calcium activity occurred as cells migrated (Fig. 1A-E). Calcium transients appeared global, unlike the localized calcium signals observed in restricted subcellular compartments in later stages of neuronal development (Hutchins and Kalil, 2008; Hutchins, 2010). To test the importance of calcium release in axophilic migration, blockage of IP3 receptors was performed in acute and chronic experiments (Figs. 1, 2). The inhibitor 2-APB was used; this inhibitor reduces calcium release through IP3 receptors as well as entry through TRP channels (Zhang et al., 2008; Li et al., 2009; Hutchins et al., 2011; Kalil et al., 2011).

Acute 2-APB application reduced the frequency of calcium transients by $21 \%$ ( $p<0.001$, paired $t$ test, $n=68, N=5$; Fig. $1 D, E)$ and also reduced the amplitude of calcium transients from $24.0 \%$ above baseline to $20.5 \%$ above baseline $(p<0.001$, paired $t$ test, $n=68, N=5)$. The relationship between calcium transients and migration speed was not frequency-dependent or amplitudedependent per se, since neither correlated with an individual cell's migration rate. However, the degree to which calcium activity was reduced relative to the baseline frequency correlated with a slowdown of migration rates, which averaged 30\% $(p<0.001$, paired $t$ test, $n=68, N=5$; Fig. $1 B-F$ ). These results indicate that IP3 receptors contribute to both the frequency and amplitude of calcium transients in GnRH neurons and that these channels are required for normal migration.

Chronic treatment with 2-APB dramatically decreased the migration of GnRH neurons (Fig. 2A-C). This treatment did not appear to reduce leading process extension (Fig. 2A,B), although the high density of GnRH-leading processes precluded quantitative analysis of their length. To determine whether blockage of TRP channels contributed to attenuated migration, explants were chronically treated with flufenamic acid or SKF-96365, broad inhibitors of TRP channels. No effect on GnRH neuronal migration was detected (Fig. 2D,E). Consistent with these results, acute application of SKF-96365 had no effect on calcium transients in migrating neurons ( $p=0.3$, paired $t$ test, $n=28, N=3$ ). However, inhibition of phospholipase C (PLC), the enzyme that produces IP3, reduced calcium transients by $35 \%(p<0.001$, paired $t$ test, $n=25, N=3)$ and migration rates by $17 \%(p=$ 
A
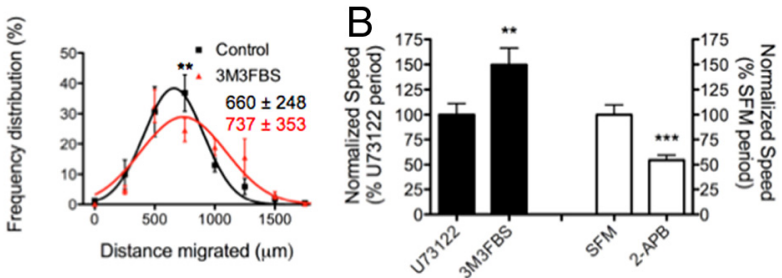

C

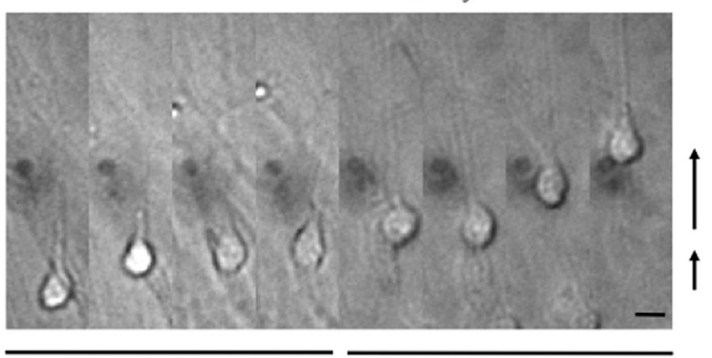

U73122 pretreat

3M3FBS

D
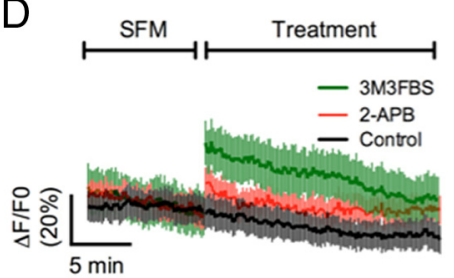

E Calcium response upon treatment

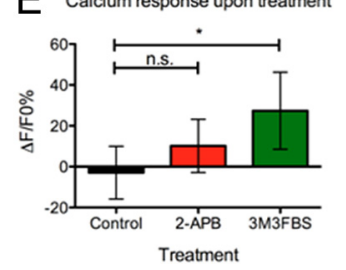

Figure 3. Stimulation of PLC promotes calcium release and accelerates axophilic migration. $\boldsymbol{A}$, Frequency distribution of distances $\mathrm{GnRH}$ neurons migrated from the center of unilateral explants chronically treated with vehicle control versus $3 \mathrm{MBFBS}$ ( $p<0.01$, 2-way ANOVA, $N=6$ explants). Fitted mean \pm SD in micrometers shown on chart. $B$, Stimulating PLC with 3M3FBS increased rates of migration in acute assays (left, ${ }^{* *} p<0.01$, paired $t$ test, $n=33$ cells, $N=5$ explants). Inhibiting endogenous IP3 receptor activity had the opposite effect (right, ${ }^{* * *} p<0.001$, paired $t$ test, $n=41$, $N=3$ ). C, Example of a GnRH neuron accelerating after PLC stimulation. Arrows denote distances moved during the imaging sessions. Scale bar, $10 \mu \mathrm{m}$. D, 3M3FBS caused a sustained calcium response for several minutes after application (line, mean; bars, SEM; $n=79$ vehicle, whole explants; 88 2-APB, whole explants; $313 \mathrm{M} 3 \mathrm{FBS}$, unilateral pit explants; $N \geq 3$ for each condition). $\boldsymbol{E}$, Calcium response $(\Delta F / F 0)$ immediately after treatment from the same dataset as $D$. ${ }^{*} p<0.05$, not significant, 1-way ANOVA with Dunnett's post-test.

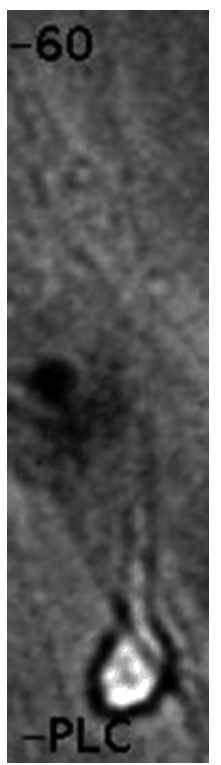

Movie 1. Stimulation of IP3 production by PLC accelerates axophilic migration. Differential interference contrast time-lapse images of a migrating $\mathrm{GnRH}$ neuron from Figure 3C, during pretreatment inhibition of PLC with U73122 (-PLC) and after stimulation of PLC with $3 \mathrm{M} 3 \mathrm{FBS}$ (+ PLC Stim). Time given in minutes, from the switch to PLC stimulation.

0.017 , paired $t$ test, $n=25, N=3)$. To verify that the changes in neuronal migration were direct and not secondary to potential growth defects in pathway axons, peripherin-positive olfactory

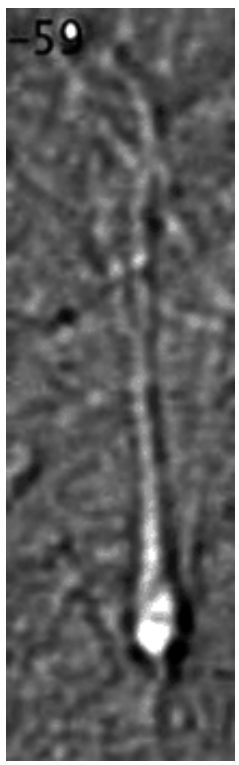

Movie 2. Inhibition of IP3 receptors slows axophilic migration. Differential interference contrast time-lapse images of a migrating $\mathrm{GnRH}$ neuron before and after the addition of an inhibitor of IP3 receptors (+2-APB). Time given in minutes, from the addition of 2-APB.

axons were stained and measured. Compared with vehicle controls, 2-APB treatment caused a modest increase in olfactory axon extension (Fig. $2 \mathrm{~F}-H$ ). However, GnRH neurons remained proximal to the main tissue of the explant, not migrating the full length of the olfactory axons available to them (Fig. $2 \mathrm{H}$ ). Fluorescence staining showed that GnRH neurons treated with 2-APB for $24 \mathrm{~h}$ had no obvious defects in their morphology or the integrity of their actin cytoskeleton labeled with phalloidin (Fig. 2I). These results support the role of calcium release through IP3 receptors in generating calcium transients and directly regulating axophilic migration.

Next, a PLC activator (3M3FBS) was chronically applied to explants to determine whether enhancing calcium release through IP3 receptors stimulated movement. No differences were detected. However, previous data showed that endogenous cues secreted by nasal cartilage facilitate migration (Giacobini et al., 2007; Toba et al., 2008; Casoni et al., 2012). Thus, it was possible that PLC was already activated, occluding the effect of pharmacological enhancement. This is consistent with the high levels of IP3 receptor-dependent calcium activity in migrating $\mathrm{GnRH}$ neurons. The nasal pit was therefore removed from surrounding tissue before plating (Kramer and Wray, 2000). In these unilateral pit explants lacking midline cues, 3M3FBS significantly increased migration of GnRH neurons in chronic treatments (Fig. 3A). This was confirmed in live imaging experiments (Fig. $3 B, C)$. To ensure increased PLC activity at the time of stimulation and not beforehand from endogenous activity, PLC was suppressed by pretreatment with U73122, which was washed out before 3M3FBS application. GnRH neuronal migration accelerated upon PLC stimulation by $50 \%$ (Fig. $3 B, C$ ), similar to the $46 \%$ reduction in speed observed on acute inhibition of IP3 receptors (Fig. 3 B, C, Movies 1,2). Measurements of calcium activity were taken during acute application of $3 \mathrm{M} 3 \mathrm{FBS}$ to unilateral explants to confirm that calcium activity was stimulated. Supporting the hypothesis that removing midline cues would reduce endogenous calcium activity, levels of calcium transients detected in GnRH cells were lower in unilateral explants than in whole explants ( 0.26 transients/min compared with 0.49 transients $/ \mathrm{min}$ in whole explants). Bath application of 3M3FBS to GnRH neurons in unilateral explants caused a sustained increase in calcium levels, but not a sustained increase in patterned calcium tran- 

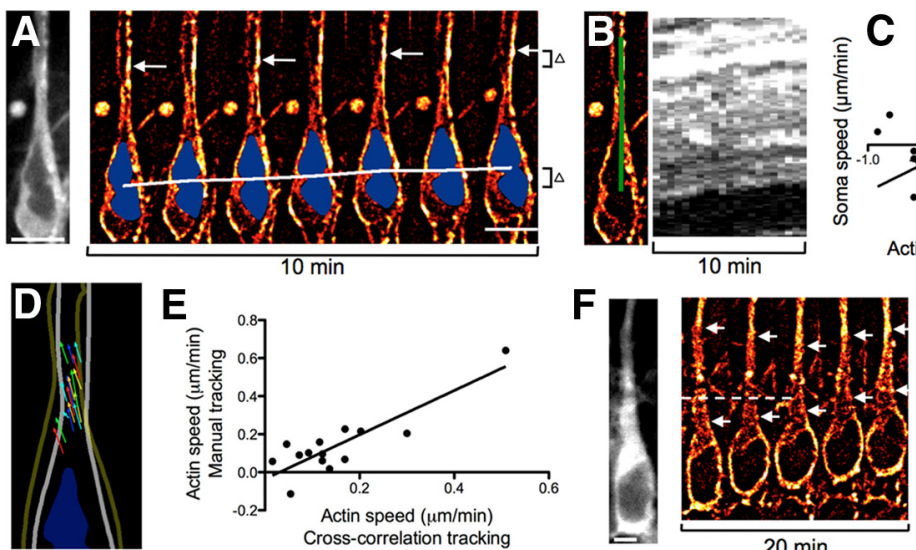

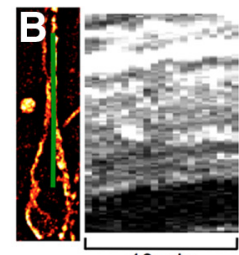

$10 \min$

$20 \mathrm{~min}$
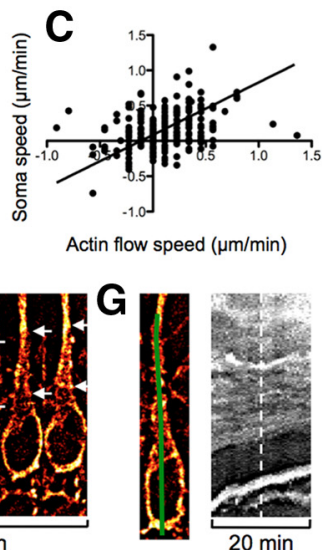

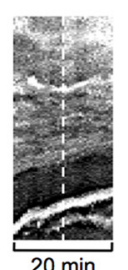

$20 \mathrm{~min}$
Figure 4. Leading process actin flow correlates with nucleokinesis. $A$, Left, Raw image of actin-GFP in a GnRH neuron. $\boldsymbol{A}$, Right, Time-lapse images of actin-GFP (sharpened) shows that movement of leading process actin (arrow) corresponded to movement of the nucleus (shaded blue, white line tracks the centroid). $\boldsymbol{B}$, Image of actin-GFP and kymograph showing movement of actin in the cell from $\boldsymbol{A}$; green line indicates region of kymograph measurements. $C$, Scatter plot showing rates of distal leading process actin flow versus nuclear movement in frame-by-frame analysis ( $p<0.001$, linear regression, $n=248$ frames from 17 neurons, $N=$ 8 explants). $\boldsymbol{D}$, Automated cross-correlation measurements of multiple regions of interest in the leading process of the cell from $A$ and $\boldsymbol{B}$, overlaid on outlines of the neuron at its start and end points. Arrows indicate the start and end points of each region of interest; multiple colors shown for image contrast. $\boldsymbol{E}$, Correlation between automated cross-correlation versus manual tracking of actin movement over the imaging period for actin-GFP expressing GnRH neurons $\left(p<0.001\right.$, simple linear regression, $R^{2}=$ $0.748, n=14$ cells from $N=5$ explants). $\boldsymbol{F}$, Raw (left) and sharpened time-lapse images of actin-GFP (right) in a GnRH neuron. Movement of leading process actin (arrows) contracting toward a central point (dotted line) for the first half of the imaging session. $\boldsymbol{G}$, Image of actin-GFP and kymograph of contraction toward a central point (from $\boldsymbol{F}$ ); green line indicates region of kymograph measurements. Dotted line denotes the time when the contraction stops. Scale bars: $A, 10 \mu \mathrm{m} ; \boldsymbol{F}, 5 \mu \mathrm{m}$.

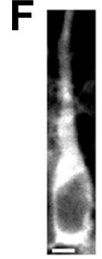

1997; He et al., 2010), was applied. An inactive, succinylated ConA was applied to explants as a negative control. ConA sharply reduced axophilic migration by $66 \%$ ( $p<0.001$, paired $t$ test, $n=88$ cells, $N=3$ explants), while succinylated ConA had no effect ( $p=0.5$, paired $t$ test, $n=$ $34, N=3$ ). Actin dynamics proximal to the soma were next examined in migrating GnRH neurons expressing actin-GFP or Lifeact-RFP. Frame-by-frame analysis revealed that actin flow in the leading process away from the soma and nuclear movement occurred simultaneously (Fig. $4 A-C$, Movie 3). Kymographs of actin movement supported this conclusion (Fig. $4 B$ ). This manual tracking method was validated with automated crosscorrelation tracking of regions-of-interest (Fig. 4D,E, see Materials and Methods). Manual and automated tracking measurements were tightly correlated in GnRH neurons expressing actin-GFP (Fig. $4 E, p<0.001$, simple linear regression, $R^{2}=0.748, n=14$ cells from $N=5$ explants). Because of bright vesicle-like puncta moving in and out of the regions of interest in Lifeact-expressing neurons, cortical actin could not be tracked with

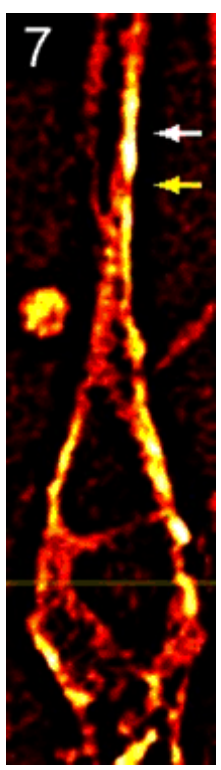

Movie 3. Leading process actin flows away from the cell body during nucleokinesis. Looped 10 min time-lapse images of actinGFP in a migrating GnRH neuron from Figure 4 A. Leading process actin (arrow) moves toward the distal leading process during nucleokinesis. The line indicates the initial position of the nucleus. Movement of the nucleus is similar to actin flow.

sients, so an analysis of fluorescence levels was performed, showing a clear rise in baseline fluorescence (Fig. $3 D, E$ ). The results of the $3 \mathrm{M} 3 \mathrm{FBS}$ experiments support a role for increased calcium release downstream of PLC stimulation. Together, these findings indicate a rapid stimulatory effect of calcium release through IP3 receptors on axophilic migration.

To examine the cytoskeletal dynamics underlying this calcium release-dependent migration, actin dynamics were monitored. Actin can mediate protrusion of the leading process tip or flow of cortical actin (actin linked to the cell membrane and associated proteins) in the soma/leading process. To test a role for cortical actin, concanavalin A (ConA), an inhibitor of cortical actin flow that does not interfere with protrusion (Canman and Bement, this automated method in these cells. Although actin in the proximal leading process flowed distally, this process did not always continue toward the distal growth cone. In some examples, proximal actin and more distal actin converged to a common point nomyosin contractions in the leading process shaft (Solecki et al., 2009). Actin contraction at the cell rear was previously shown to push cortical interneurons forward (Martini and Valdeolmillos, 2010). Consistent with this, active actin accumulations at the rear of GnRH neurons were detected during movement (Fig. 5A, Movie 5). Residuals analysis (Fig. 5B; see Materials and Methods) showed that rear actin contractions contribute significantly to

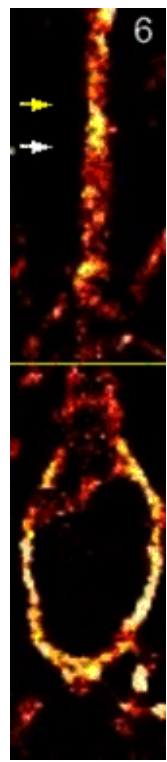

Movie 4. Contractions in theleading process draw actin in the proximal and distal leading process toward a central point. Looped 20 min time-lapse images of actin-GFP in a migrating GnRH neuron from Figure 4 F. Distal leading process actin (arrow), unlike the proximal actin, moves toward the nucleus rather than away. The line indicates the center of the contraction. All actin flows away from the growth cone after the contraction ceases, possibly due to actinomyosin contractions in more distal segments of the leading process. (Fig. 4F, G, Movie 4), suggesting that actin flow may reflect acti- 
movement (by $\sim 7 \mu \mathrm{m} / \mathrm{h}$ during contractions; Fig. $5 C$ ) after accounting for the effects of leading process actin flow.

Leading process actin flow and rear actin contraction were both tested downstream of calcium signaling. Changes in actin flow rates after the addition of 2-APB were monitored. Actin flow was sharply reduced by $2-\mathrm{APB}$ with a corresponding slowdown of the cell body (Fig. 6, Movies 6,7). These data demonstrate that distal actin flow in the leading process is dependent on IP3 receptors. In contrast, actin contraction at the rear of the cell appeared unaffected by 2-APB, suggesting that the contribution of IP3 receptors to rear actin contraction is minimal. If leading process actin flow mediates calcium release-dependent migration, then stimulating PLC should induce this actin flow. PLC stimulation caused robust actin flow toward the distal leading process coupled to accelerated migration (Fig. 7, Movie 8). The changes in movement after manipulating calcium release (either inhibition or stimulation) did not reflect an altered relationship between actin and soma speeds (Figs. 6D, 7F).

The mechanisms linking calcium activity to changes in neuronal cytoskeleton during nucleokinesis are unknown. Several candidate pathways were tested in chronic migration assays (Fig. 8). First, two calcium sensing proteins, CaMKK and CaMKII (calcium/ calmodulin-dependent protein kinasekinase and kinase-II), were examined. While inhibition of CaMKII had no effect, inhibition of CaMKK significantly reduced migration (Fig. 8A-C). Signaling pathways operating through phosphorylation of myosin II were tested, since this regulates cortical actin flow ( $\mathrm{He}$ et al., 2010). CaMKK could signal to myosin II through CaMKI (calcium/calmodulindependent protein kinase I) and ERK (extracellular signal-regulated kinase) (Schmitt et al., 2004), in turn phosphorylating myosin light-chain kinase (MLCK) to stimulate migration (Huang et al., 2004). Alternatively, CaMKK can activate AMPK (Hurley et al., 2005), though a role for this pathway in neuronal migration is controversial (Amato et al., 2011; Williams et al., 2011). Surprisingly, inhibition of AMPK but not MLCK reduced axophilic migration (Fig. 8D,E). AMPK can disinhibit myosin II phosphorylation by activating RhoA/ROCK (Bultot et al., 2009) to inhibit myosin light-chain phosphatase. Accordingly, inhibition of RhoA/ROCK signaling with Y-27632 potently inhibited migration (Fig. 8A,F). Application of Y-27632 significantly enhanced olfactory axon elongation (Fig. 8G,H) while halting axophilic migration. These results show that pathway olfactory axon extension is dissociated from neuronal migration in this signaling pathway. Importantly, analysis of the number of GnRH neurons in control versus pharmacological treatments revealed no differences in control versus treated explants (Table 1). After $24 \mathrm{~h}$ of treatment with Y-27632, the actin cytoskeleton appeared robust, healthy, and similar to controls (Fig. 8I). This suggests that while these signaling pathway manipulations reduce axophilic migration, the cytoskeleton remains prepared to resume normal migration at any time.

If AMPK and RhoA/ROCK operate downstream of calcium signaling, manipulation of these effectors should supersede the effects of manipulating calcium release through IP3 receptors. GnRH neurons were pretreated with AICAR to activate AMPK, and the change in speed was monitored after application of 2-APB. While 2-APB normally attenuated speed, stimulation of AMPK prevented

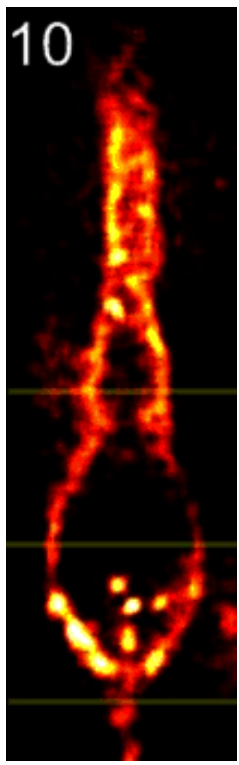

Movie 5. Actin compression at the cell rear contributes to forward movement. Looped 20 min time-lapse images of Lifeact-RFP in a migrating $\mathrm{GnRH}$ neuron from Figure $5 \mathrm{~A}$. Actin compresses at the rear of the cell to push the nucleus forward. Lines indicate the initial borders and center of the cell body.

Figure 5. Actin contractions at the cell rear contribute to migration rates. $\boldsymbol{A}$, Time series of Lifeact-RFP (sharpened) in a GnRH neuron contractions. C, Frames without rear actin contractions ( $n=90$ frames) had no net residual soma speed (blue, $p>0.05,1$-sample $t$ test). Frames with rear actin contractions $(n=45)$ had a net residual movement of $0.13 \mu \mathrm{m} / \mathrm{min}$ (red, $p<0.01,1$-sample $t$ test).

this slowdown (Fig. 8J). Furthermore, pretreatment with Y-27632 to inhibit RhoA/ROCK signaling prevented the acceleration normally caused when stimulating PLC (Fig. $8 \mathrm{~J}$ ). Acute application of Y-27632 did not significantly alter calcium transients (mean change in frequency: $0.045 \pm 0.030$ transients $/ \mathrm{min}$, $p=0.13$, paired $t$ test, $n=66$ cells from $N=3$ explants). GnRH neurons in unilateral explants with lower natural levels of calcium release would be predicted to accelerate in response to AMPK stimulation. In fact, acute treatment of unilateral explants with AICAR accelerated GnRH migration rates by $38 \%(p<$ 0.01 , paired $t$ test, $n=77, N=3$ ). This series of experiments connects, for the first time, the calcium signals observed to accelerate migration to key regulators of the actin dynamics that mediated nucleokinesis. These results indicate that calcium release through IP3 receptors induces migration of GnRH neurons through a signaling pathway dependent on the calcium sensor CaMKK, activating downstream kinases AMPK and RhoA/ ROCK, directly influencing actinomyosin contraction in the leading process to draw the nucleus forward during axophilic migration.

\section{Discussion}

The present work investigated the relationship between calcium signals, cytoskeletal dynamics, and migration rates during axophilic migration of GnRH neurons. Together, the results indicate that calcium release through IP3 receptors selectively stimulates leading process actin flow away from the nucleus during axo- 

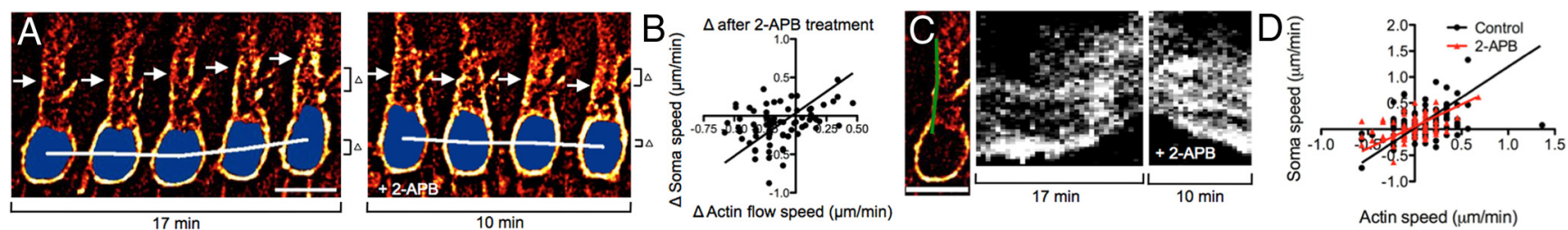

Figure 6. Calcium release through IP3 receptors is required for leading process actin flow. A, Time-lapse images of actin-GFP in a GnRH neuron (sharpened). During a control imaging period (left), leading process actin begins rapid distal flow (arrows) concomitant with nucleokinesis (line). Inhibiting IP3 receptors (right) halts this process. Scale bar, $10 \mu \mathrm{m}$. B, Scatter plot of the change in actin flow and soma speeds after treatment with 2-APB ( $p<0.01$, linear regression, $n=75$ frames from 8 neurons, $N=5$ explants). C, Image of actin-GFP and kymograph showing actin movement during the control and 2-APB treatment periods from $A$. Green line indicates region of kymograph measurements. $\boldsymbol{D}$, Inhibiting IP3 receptors did not alter the relationship between leading process actin movement and soma speed (difference in regression slopes, $p>0.05$ ), but rather shifted these speeds lower.
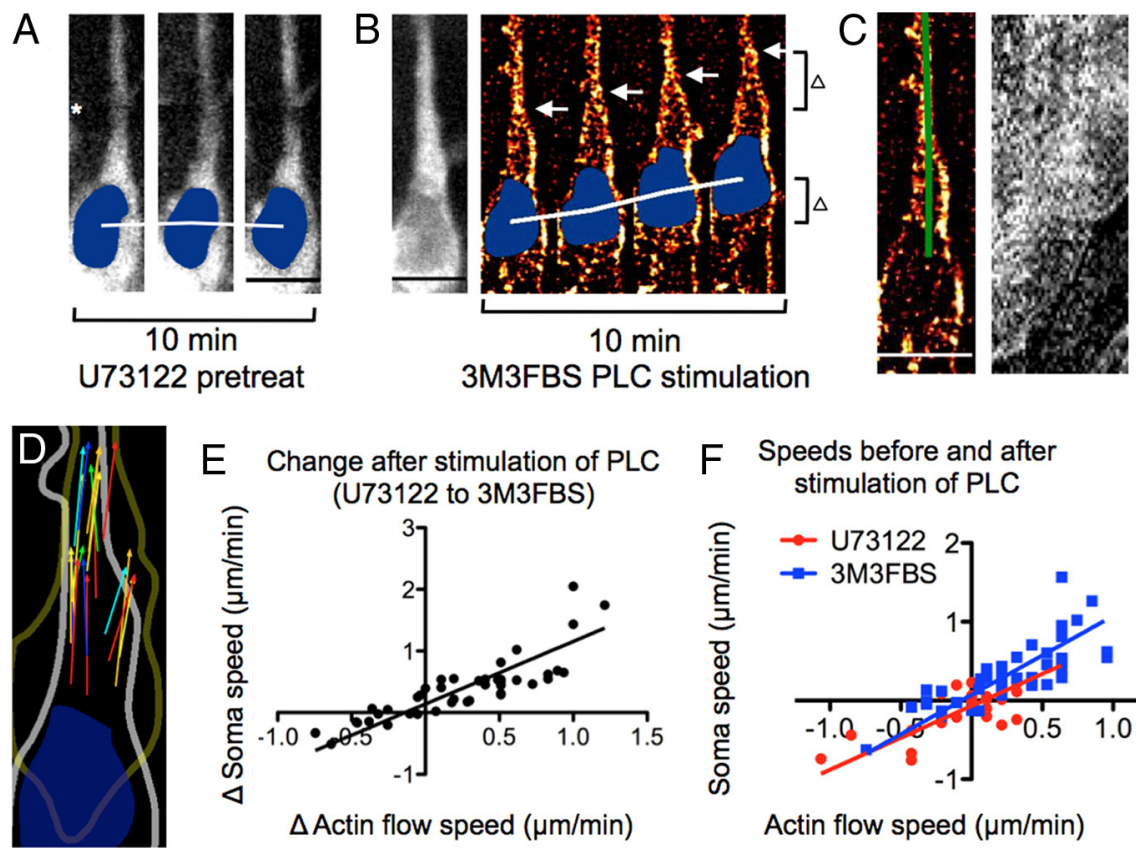

Speeds before and after
stimulation of PLC

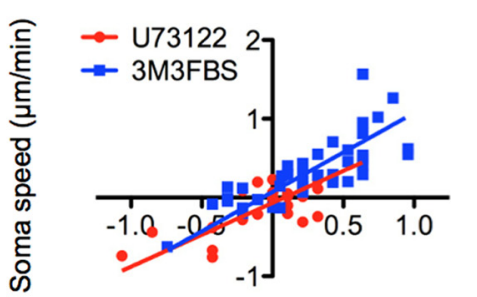

Actin flow speed $(\mu \mathrm{m} / \mathrm{min})$

Figure 7. Stimulation of PLCleads to actin flow.A,Actin-GFP fluorescence images showing a stalled GnRH neuron during pretreatment inhibition of endogenous PLC activity. Image stitched together from different $z$-planes at the asterisk. $\boldsymbol{B}$, Left, Actin-GFP fluorescence of the same cell as $\boldsymbol{A}$ at the time of PLC stimulation. $\boldsymbol{B}$, Right, Time-lapse images of actin-GFP (sharpened) highlighting simultaneous leading process actin flow (arrows) and nuclear movement evoked by PLC stimulation. $\boldsymbol{C}$, Image of actin-GFP and kymograph of actin movement during 20 min of PLC stimulation (same cell as $\boldsymbol{B}$ ). Green line indicates region of kymograph measurements. $\boldsymbol{D}$, Automated cross-correlation measurements of multiple regions of interestin the leading process of the cell from $B$ and $C$, overlaid on outlines of the neuron atits start and end points. Arrows indicate the start and end points of each region of interest; multiple colors shown for image contrast. $\boldsymbol{E}$, Scatter plot of the change after stimulation of PLC in actin flow and soma speeds $(p<0.001$, linear regression, $n=43$ frames from 7 neurons, $N=3$ explants,). $\boldsymbol{F}$, Stimulating IP3 production did not alter the relationship between leading process actin movement and soma speed (difference in regression slopes, $p>0.05$ ), but rather shifted these speeds higher. Scale bars, $10 \mu \mathrm{m}$.

philic migration. In addition, signal transduction pathways linking calcium to the cytoskeletal dynamics underlying nucleokinesis were examined. Here, we identified a novel mechanism initiated by the calcium sensor CaMKK to actin/myosin through AMPK activation of RhoA/ROCK. This mechanism promotes axophilic migration. Thus, neurons exhibiting axophilic migration have developed a unique strategy to overcome the challenges faced along their pathway.

Calcium signaling regulates diverse and distinct aspects of migration through mechanisms that are unclear. While studies have shown that CGN migration is regulated by calcium transients in a frequency-dependent manner (Komuro and Kumada, 2005; Kumada et al., 2009; Fahrion et al., 2012), migrating cortical interneurons display complex calcium patterns that are difficult to correlate with movement (Moya and Valdeolmillos, 2004; Bortone and Polleux, 2009; Martini and Valdeolmillos, 2010). The present experi- ments demonstrate that calcium release through IP3 receptors regulates axophilic migration, with reduced migration rates showing a proportional reduction to the frequency of calcium transients. However, these migration rates were not directly related to the absolute frequency of calcium transients as in CGNs. This suggests that additional channels not directly involved in migration may contribute to cytosolic calcium signals. For example, L-type calcium channels are known to play a role in GnRH development (Constantin et al., 2010) but blocking these does not reduce migration (Toba et al., 2005). Certainly, calcium channel clustering to distinct microdomains may impart additional signaling specificity to the global calcium signals monitored (Augustine et al., 2003; Willoughby et al., 2010; Wheeler et al., 2012).

Leading process growth cone protrusion is required for normal migration rates of hippocampal neurons and CGNs, since leading process extension is a prerequisite for nucleokinesis in these cells. The signal transduction pathway for this protrusion is mediated by calcium influx, which stimulates F-actin through Lisl, the cytoskeletal scaffolding protein IQGAP1 and the Rho family GTPase, Cdc42 (Kholmanskikh et al., 2006). We showed that in migrating $\mathrm{GnRH}$ neurons, calcium release influenced RhoA-mediated actinomyosin contraction in the leading process. Since Rho family GTPases frequently cross-inhibit the effects of one another (Yuan et al., 2003); preferential activation in different subcellular compartments may facilitate migration by causing actin protrusion versus contractility in only the appropriate part of the cell. RhoA can be stimulated by AMPK, a kinase activated by the calcium sensor CaMKK (Bultot et al., 2009), and AMPK was found to enhance axophilic migration. In contrast, AMPK was found to be dispensable for radial migration of cortical neurons (Amato et al., 2011; Williams et al., 2011). This difference may be a consequence of the large number of signals GnRH neurons must integrate in their complicated journey to penetrate the brain and disperse to their appropriate forebrain locations (Wray, 2010). In addition, this signaling pathway may separate neurons exhibiting axophilic migration from their outgrowing axonal pathway and decrease the odds of a single mutation/perturbation disrupting two systems. 


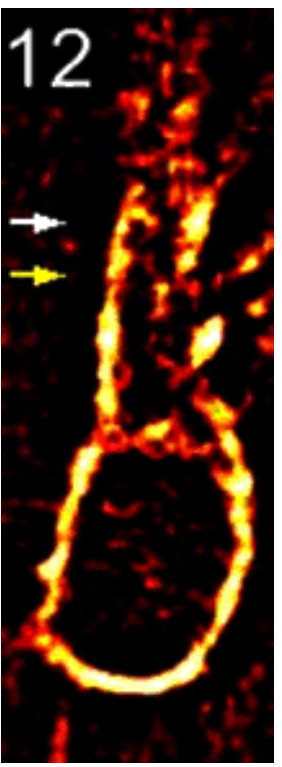

Movie 6. Leading process actin flow at the initiation of nucleokinesis in a control period. Looped 17 min time-lapse images of actin-GFP in a migrating GnRH neuron from Figure 6. As actin moves up the leading process (arrow), the front edge of the nucleus begins its initial stage of forward movement.

Axophilic migration requires an intricate orchestration of developmental events involving several cell types (Forni and Wray, 2012). Perturbation of axon growth can deprive migratory neurons of their pathway. Some molecular signaling pathways disrupt both olfactory axon growth and GnRH neuronal migration (Watanabe et al., 2009), making it challenging to disentangle the effects on the system as a whole from the specific effects on axophilic migration. Importantly, in the present study, the reduction of migration rates from blocking the identified signaling pathway did not occur by stunting the growth of the olfactory axons along which the GnRH neurons migrate. The increased growth of olfactory axons when blocking components of this pathway demonstrated a robust decoupling of signaling mechanisms in axon growth from cell migration.

Several cytoskeletal mechanisms have recently been proposed to mediate nucleokinesis during neuronal migration (Bellion et al., 2005; Schaar and McConnell, 2005; Solecki et al., 2009; Asada and Sanada, 2010; He et al., 2010; Martini and Valdeolmillos, 2010). Actinomyosin-based mechanisms were proposed to facilitate movement of the nucleus into swellings in the leading process by squeezing cells forward from behind and/or breaking adhesions (Schaar and McConnell, 2005; Martini and Valdeolmillos, 2010). Alternatively, contractions in the leading process actinomyosin (Solecki et al., 2009) or growth cone (He et al., 2010) were proposed to draw the nucleus forward. Notably, these different mechanisms were observed to occur in different cell types. Our results suggest that axophilic migration mechanisms involve concurrent activation of the rear actin contraction that drives migrating cortical interneurons (Martini and Valdeolmillos, 2010) as well as leading process actin translocation observed in glia-guided radial migration of cerebellar granule neurons (Solecki et al., 2009). While in cortical interneurons rear actin contractions are sufficient to push the nucleus forward (Martini and Valdeolmillos, 2010), those activated during axophilic migration discontinue before complete nucleokinesis. Axophilic migration thus appears to be intermediate to cortical interneurons and dissociated CGNs, which do not require rear actinomyosin activity (He et al., 2010). In addition, we observed that rear actin contractions were unaffected by blocking IP3 receptors. This suggests that the cytoskeletal dynamics in different cellular compartments are regulated through independent signaling mechanisms.

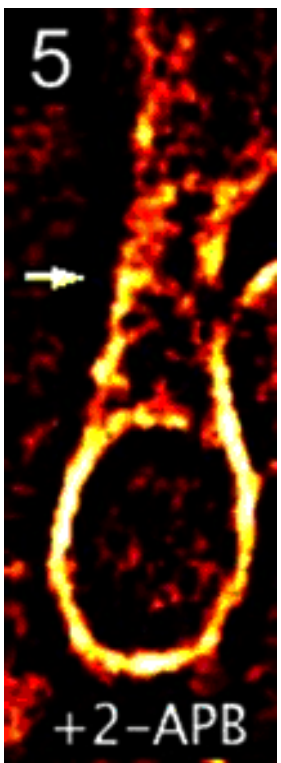

Movie 7. Leading process actin flow and nucleokinesis halt during inhibition of IP3 receptors. Same cell as Movie 6. Looped 10 min time-lapse images of actin-GFP in a GnRH neuron from Figure 6 after addition of 2-APB. The white arrow tracks leading process actin. The initial stage of nucleokinesis, begun in the control period shown in Movie 6, ceases, forward flow of leading process actin and nucleokinesis stop, and the cell returns to its initial state.

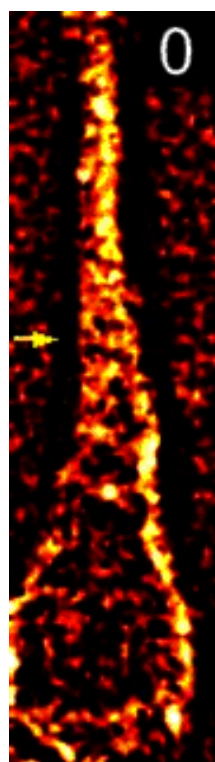

Movie 8. Stimulation of IP3 production rapidly accelerates axophilic migration. Looped 20 min time-lapse images of actinGFP in a previously stationary GnRH neuron (from Fig. 7) during stimulation of PLC with 3M3FBS. Leading process actin movement (arrow) toward the distal growth cone and nucleokinesis are both dramatically enhanced.
Neurons migrating along the anteroposterior axis combine homophilic and axophilic mechanisms to arrive at their target locations. This has been observed in the rostrocaudal migration of GnRH neurons (Wray, 2002), neurons from the lower rhombic lip (Ono et al., 2004), and facial branchial motor neurons (Paulus and Halloran, 2006; Mapp et al., 2010). Immature olfactory interneurons in the rostral migratory stream are an exception, traversing an extension of the lateral ventricle rather than an axon tract (Curtis et al., 2009). Some neural populations migrating along the mediolateral axis also use axophilic mechanisms, such as lower rhombic lip neurons destined for the medulla oblongata (Ono et al., 2004). Many other neural populations migrate along the anteroposterior axis, such as early CGNs before their tangential migration (Ryder and Cepko, 1994) and several hindbrain populations (Farago et al., 2006; Pasqualetti et al., 2007). Whether these neurons also undergo axophilic migration is not known. In addition to neuronal migration, oligodendrocytes and olfactory ensheathing cells engage in axophilic migration, often assuming similar morphologies to migratory neurons. Thus, the mechanisms of axophilic migration described here have broad implications for the migration of other CNS populations. 
A
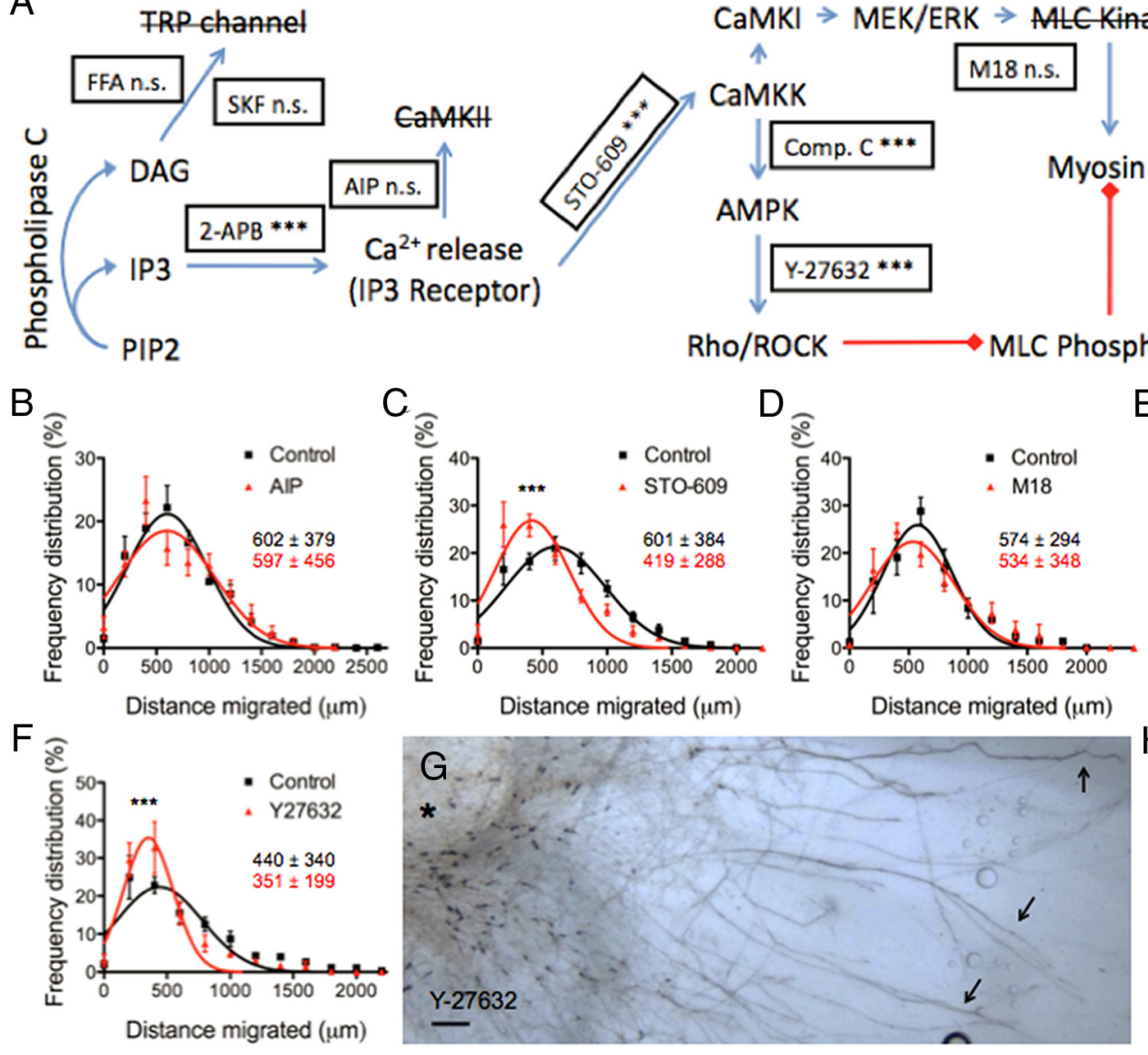

D

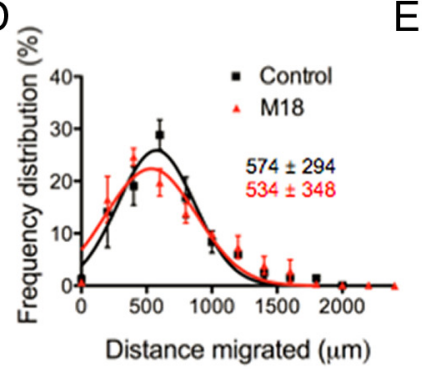

$\mathrm{H}$

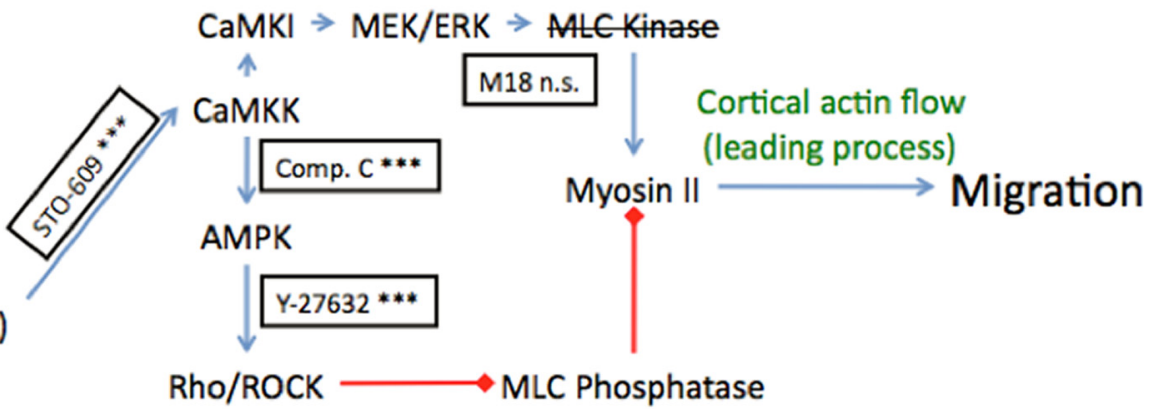

I

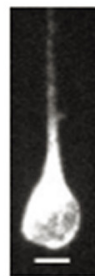

$\mathrm{GnRH}$
Control

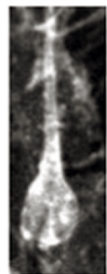

F-actin

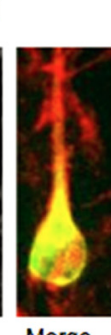

Merge
Y-27632

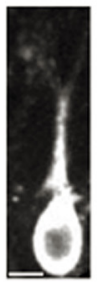

$\mathrm{GnRH}$

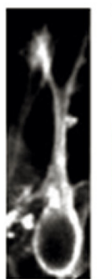

F-actin
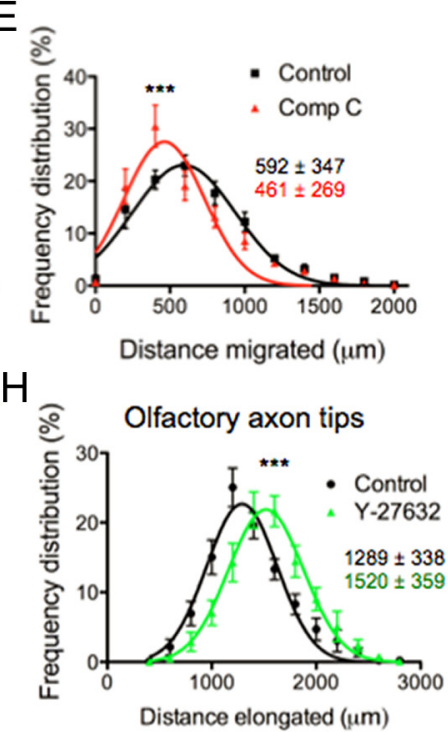

Distance elongated $(\mu \mathrm{m})$

Figure 8. Downstream signaling pathways during axophilic migration. $\boldsymbol{A}$, Hypothesized signaling pathway. Components of this signaling pathway were tested in chronic treatment assays with the pharmacological inhibitors shown in boxes $\left({ }^{* *} p<0.001\right.$, not significant, $p>0.05$; see $\left.\boldsymbol{B}-\boldsymbol{F}\right)$. Strikethrough indicates the pathway was excluded. $\boldsymbol{B}-\boldsymbol{F}$, Frequency distributions and best-fit Gaussian distribution curves (fitted mean $\pm S D$ in micrometers shown on chart) of distances $G n R H$ neurons migrated in chronic treatment migration assays (as in Fig. $2 A, B$ ). Vehicle control versus autocamtide-2-related inhibitory peptide (AIP) $(\boldsymbol{B}, p>0.05, N=6$ explants), ST0-609 (C, $p<0.001, N \geq 9), \operatorname{M18}(\boldsymbol{D}, p>0.05, N=3)$, Compound $(\boldsymbol{E}, p<0.001, N \geq 9)$, and Y27632 (F, $p<0.001, N \geq 7)$. $\boldsymbol{G}, 0$ lfactory axons (brown, arrows, immunostained for peripherin) showed robust growth while GnRH neurons (dark blue, immunostained for GnRH) remained near the main tissue mass (left edge) during $Y$-27632 treatment. $\boldsymbol{H}$, Frequency distribution of the elongation distances of the olfactory axons from the tip of the nasal cartilage. Blocking RhoA/ROCK signaling enhanced olfactory axon elongation ${ }^{* * *} p<0.01,2$-way ANOVA, $N=$ 8). $I$, Examples of GnRH neurons labeled with GnRH immunofluorescence and phalloidin, treated with vehicle or Y-27632 for $24 \mathrm{~h}$. Actin organization appears similar in each example. Scale bar, $5 \mu \mathrm{m}$. J, Left, Activating AMPK with AICAR prevented the slowdown normally caused by 2-APB $\left({ }^{* * *} p<0.001\right.$, not significant, $p>0.05,1$-sample $t$ test, $\left.n \geq 35, N \geq 3\right)$. J, Right, Inhibiting Rho/ROCK signaling with Y-27632 prevented the acceleration normally observed when stimulating PLC ( ${ }^{* *} p<0.001$, not significant, $p>0.05,1$-sample $t$ test, $n \geq 29, N \geq 3$ ).

Table 1. Number of GnRH neurons was unaffected by chronic pharmacological manipulation

\begin{tabular}{|c|c|c|c|c|c|c|c|c|c|}
\hline $\begin{array}{l}\text { GnRH cell } \\
\text { number }\end{array}$ & 2-APB & SKF-96365 & $\begin{array}{l}\text { Flufenamic } \\
\text { acid }\end{array}$ & $\begin{array}{l}\text { 3M3FBS } \\
\text { (unilateral) }\end{array}$ & $\begin{array}{l}\text { Autocamtide- } \\
\text { 2-related inhibitory } \\
\text { peptide }\end{array}$ & ST0-609 & M18 & Compound C & Y27632 \\
\hline Control & $\begin{array}{l}337.6 \pm 39.2 \\
N=10\end{array}$ & $\begin{array}{l}534.1 \pm 38.3 ; \\
N=7\end{array}$ & $\begin{array}{l}460.1 \pm 73.4 \\
N=8\end{array}$ & $\begin{array}{l}182.2 \pm 30.9 ; \\
N=6\end{array}$ & $\begin{array}{l}570.8 \pm 60.0 \\
N=6\end{array}$ & $\begin{array}{l}339.1 \pm 39.3 \\
N=10\end{array}$ & $\begin{array}{l}478.0 \pm 75.9 \\
N=3\end{array}$ & $\begin{array}{l}379.8 \pm 39.2 \\
N=10\end{array}$ & $\begin{array}{l}432.4 \pm 51.5 ; \\
N=8\end{array}$ \\
\hline Treatment & $\begin{array}{l}413.6 \pm 69.1 ; \\
N=11\end{array}$ & $\begin{array}{l}443.0 \pm 63.6 ; \\
N=7\end{array}$ & $\begin{array}{l}440.1 \pm 66.8 \\
N=8\end{array}$ & $\begin{array}{l}147.2 \pm 15.7 \\
N=6\end{array}$ & $\begin{array}{l}548.7 \pm 99.4 \\
N=6\end{array}$ & $\begin{array}{l}342.7 \pm 36.6 ; \\
N=9\end{array}$ & $\begin{array}{l}398.3 \pm 121.9 \\
N=3\end{array}$ & $\begin{array}{l}452.3 \pm 58.1 \\
N=9\end{array}$ & $\begin{array}{l}347.0 \pm 74.7 ; \\
N=7\end{array}$ \\
\hline
\end{tabular}

Mean number of cells \pm SEM. All comparisons between control and treatment groups: $p>0.05$ by one-way ANOVA with Bonferroni's post-test. $N$, number of independent explants. 


\section{Notes}

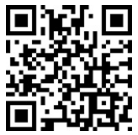

A movie of the calcium imaging from the cell shown in Figure $1 B$ can be seen on Youtube or at the lab website: http://youtu.be/YP2Kldc1hR0;

http://neuroscience.nih.gov/Lab.asp?Org_ID $=42$.

To view this movie, smartphone users can scan this $\mathrm{QR}$ code with an appropriate app (e.g., Google Goggles for Android; the Scan app, the Bakodo app, or the goggles function in Google Search for iPhones; or the scan function of the Bing search app on Windows Phone). For details about hosting videos and generating QR codes, see Hutchins (2013).

\section{References}

Amato S, Liu X, Zheng B, Cantley L, Rakic P, Man HY (2011) AMPactivated protein kinase regulates neuronal polarization by interfering with PI 3-kinase localization. Science 332:247-251. CrossRef Medline

Asada N, Sanada K (2010) LKB1-mediated spatial control of GSK3 $\beta$ and adenomatous polyposis coli contributes to centrosomal forward movement and neuronal migration in the developing neocortex. J Neurosci 30:8852-8865. CrossRef Medline

Augustine GJ, Santamaria F, Tanaka K (2003) Local calcium signaling in neurons. Neuron 40:331-346. CrossRef Medline

Bando Y, Hirano T, Tagawa Y (2012) Dysfunction of KCNK potassium channels impairs neuronal migration in the developing mouse cerebral cortex. Cereb Cortex. Advance online publication. Retrieved April 15, 2013. doi:10.1093/cercor.bhs387. CrossRef Medline

Bellion A, Baudoin JP, Alvarez C, Bornens M, Métin C (2005) Nucleokinesis in tangentially migrating neurons comprises two alternating phases: forward migration of the Golgi/centrosome associated with centrosome splitting and myosin contraction at the rear. J Neurosci 25:5691-5699. CrossRef Medline

Bortone D, Polleux F (2009) KCC2 expression promotes the termination of cortical interneuron migration in a voltage-sensitive calcium-dependent manner. Neuron 62:53-71. CrossRef Medline

Bultot L, Horman S, Neumann D, Walsh MP, Hue L, Rider MH (2009) Myosin light chains are not a physiological substrate of AMPK in the control of cell structure changes. FEBS Lett 583:25-28. CrossRef Medline

Cancedda L, Fiumelli H, Chen K, Poo MM (2007) Excitatory GABA action is essential for morphological maturation of cortical neurons in vivo. J Neurosci 27:5224-5235. CrossRef Medline

Canman JC, Bement WM (1997) Microtubules suppress actomyosin-based cortical flow in Xenopus oocytes. J Cell Sci 110:1907-1917. Medline

Casoni F, Hutchins BI, Donohue D, Fornaro M, Condie BG, Wray S (2012) SDF and GABA interact to regulate axophilic migration of GnRH neurons. J Cell Sci 125:5015-5025. CrossRef Medline

Constantin S, Klenke U, Wray S (2010) The calcium oscillator of GnRH-1 neurons is developmentally regulated. Endocrinology 151:3863-3873. CrossRef Medline

Curtis MA, Monzo HJ, Faull RL (2009) The rostral migratory stream and olfactory system: smell, disease and slippery cells. Prog Brain Res 175:3342. CrossRef Medline

Fahrion JK, Komuro Y, Li Y, Ohno N, Littner Y, Raoult E, Galas L, Vaudry D, Komuro H (2012) Rescue of neuronal migration deficits in a mouse model of fetal Minamata disease by increasing neuronal $\mathrm{Ca} 2+$ spike frequency. Proc Natl Acad Sci U S A 109:5057-5062. CrossRef Medline

Farago AF, Awatramani RB, Dymecki SM (2006) Assembly of the brainstem cochlear nuclear complex is revealed by intersectional and subtractive genetic fate maps. Neuron 50:205-218. CrossRef Medline

Fischer M, Kaech S, Wagner U, Brinkhaus H, Matus A (2000) Glutamate receptors regulate actin-based plasticity in dendritic spines. Nat Neurosci 3:887-894. CrossRef Medline

Forni PE, Wray S (2012) Neural crest and olfactory system: new prospective. Mol Neurobiol 46:349-360. CrossRef Medline

Giacobini P, Messina A, Wray S, Giampietro C, Crepaldi T, Carmeliet P, Fasolo A (2007) Hepatocyte growth factor acts as a motogen and guidance signal for gonadotropin hormone-releasing hormone-1 neuronal migration. J Neurosci 27:431-445. CrossRef Medline

Guan CB, Xu HT, Jin M, Yuan XB, Poo MM (2007) Long-range Ca2+ signaling from growth cone to soma mediates reversal of neuronal migration induced by slit-2. Cell 129:385-395. CrossRef Medline
He M, Zhang ZH, Guan CB, Xia D, Yuan XB (2010) Leading tip drives soma translocation via forward F-actin flow during neuronal migration. J Neurosci 30:10885-10898. CrossRef Medline

Huang C, Jacobson K, Schaller MD (2004) MAP kinases and cell migration. J Cell Sci 117:4619-4628. CrossRef Medline

Hurley RL, Anderson KA, Franzone JM, Kemp BE, Means AR, Witters LA (2005) The Ca2+/calmodulin-dependent protein kinase kinases are AMP-activated protein kinase kinases. J Biol Chem 280:29060-29066. CrossRef Medline

Hutchins BI (2010) Competitive outgrowth of neural processes arising from long-distance cAMP signaling. Sci Signal 3:jc1. CrossRef Medline

Hutchins BI (2013) Embed dynamic content in your poster. Sci Signal 6:tr1. CrossRef Medline

Hutchins BI, Kalil K (2008) Differential outgrowth of axons and their branches is regulated by localized calcium transients. J Neurosci 28:143153. CrossRef Medline

Hutchins BI, Li L, Kalil K (2011) Wnt/calcium signaling mediates axon growth and guidance in the developing corpus callosum. Dev Neurobiol 71:269-283. CrossRef Medline

Kalil K, Li L, Hutchins BI (2011) Signaling mechanisms in cortical axon growth, guidance, and branching. Front Neuroanat 5:62. CrossRef Medline

Kholmanskikh SS, Koeller HB, Wynshaw-Boris A, Gomez T, Letourneau PC, Ross ME (2006) Calcium-dependent interaction of Lis1 with IQGAP1 and Cdc42 promotes neuronal motility. Nat Neurosci 9:50-57. CrossRef Medline

Klenke U, Taylor-Burds C (2012) Culturing embryonic nasal explants for developmental and physiological study. Curr Protoc Neurosci Chapter 3, Unit 3.25: 21-16. CrossRef Medline

Komuro H, Kumada T (2005) Ca2+ transients control CNS neuronal migration. Cell Calcium 37:387-393. CrossRef Medline

Komuro H, Yacubova E, Yacubova E, Rakic P (2001) Mode and tempo of tangential cell migration in the cerebellar external granular layer. J Neurosci 21:527-540. Medline

Kramer PR, Wray S (2000) Midline nasal tissue influences nestin expression in nasal-placode-derived luteinizing hormone-releasing hormone neurons during development. Dev Biol 227:343-357. CrossRef Medline

Kumada T, Jiang Y, Kawanami A, Cameron DB, Komuro H (2009) Autonomous turning of cerebellar granule cells in vitro by intrinsic programs. Dev Biol 326:237-249. CrossRef Medline

Li L, Hutchins BI, Kalil K (2009) Wnt5a induces simultaneous cortical axon outgrowth and repulsive axon guidance through distinct signaling mechanisms. J Neurosci 29:5873-5883. CrossRef Medline

Mapp OM, Wanner SJ, Rohrschneider MR, Prince VE (2010) Pricklelb mediates interpretation of migratory cues during zebrafish facial branchiomotor neuron migration. Dev Dyn 239:1596-1608. CrossRef Medline

Martini FJ, Valdeolmillos M (2010) Actomyosin contraction at the cell rear drives nuclear translocation in migrating cortical interneurons. J Neurosci 30:8660-8670. CrossRef Medline

Martini FJ, Valiente M, López Bendito G, Szabó G, Moya F, Valdeolmillos M, Marín O (2009) Biased selection of leading process branches mediates chemotaxis during tangential neuronal migration. Development 136:4150. CrossRef Medline

Moya F, Valdeolmillos M (2004) Polarized increase of calcium and nucleokinesis in tangentially migrating neurons. Cereb Cortex 14:610-618. CrossRef Medline

Nadarajah B, Brunstrom JE, Grutzendler J, Wong RO, Pearlman AL (2001) Two modes of radial migration in early development of the cerebral cortex. Nat Neurosci 4:143-150. CrossRef Medline

Ono K, Yasui Y, Ikenaka K (2004) Lower rhombic lip-derived cells undergo transmedian tangential migration followed by radial migration in the chick embryo brainstem. Eur J Neurosci 20:914-922. CrossRef Medline

Pasqualetti M, Díaz C, Renaud JS, Rijli FM, Glover JC (2007) Fate-mapping the mammalian hindbrain: segmental origins of vestibular projection neurons assessed using rhombomere-specific Hoxa2 enhancer elements in the mouse embryo. J Neurosci 27:9670-9681. CrossRef Medline

Paulus JD, Halloran MC (2006) Zebrafish bashful/laminin-alpha 1 mutants exhibit multiple axon guidance defects. Dev Dyn 235:213-224. CrossRef Medline

Riedl J, Flynn KC, Raducanu A, Gärtner F, Beck G, Bösl M, Bradke F, Massberg S, Aszodi A, Sixt M, Wedlich-Söldner R (2010) Lifeact mice for studying F-actin dynamics. Nat Methods 7:168-169. CrossRef Medline 
Ryder EF, Cepko CL (1994) Migration patterns of clonally related granule cells and their progenitors in the developing chick cerebellum. Neuron 12:1011-1028. CrossRef Medline

Schaar BT, McConnell SK (2005) Cytoskeletal coordination during neuronal migration. Proc Natl Acad Sci U S A 102:13652-13657. CrossRef Medline

Schmitt JM, Wayman GA, Nozaki N, Soderling TR (2004) Calcium activation of ERK mediated by calmodulin kinase I. J Biol Chem 279:2406424072. CrossRef Medline

Solecki DJ, Trivedi N, Govek EE, Kerekes RA, Gleason SS, Hatten ME (2009) Myosin II motors and F-actin dynamics drive the coordinated movement of the centrosome and soma during CNS glial-guided neuronal migration. Neuron 63:63-80. CrossRef Medline

Toba Y, Pakiam JG, Wray S (2005) Voltage-gated calcium channels in developing GnRH-1 neuronal system in the mouse. Eur J Neurosci 22:7992. CrossRef Medline

Toba Y, Tiong JD, Ma Q, Wray S (2008) CXCR4/SDF-1 system modulates development of GnRH-1 neurons and the olfactory system. Dev Neurobiol 68:487-503. CrossRef Medline

Tsai JW, Bremner KH, Vallee RB (2007) Dual subcellular roles for LIS1 and dynein in radial neuronal migration in live brain tissue. Nat Neurosci 10:970-979. CrossRef Medline

Watanabe Y, Inoue K, Okuyama-Yamamoto A, Nakai N, Nakatani J, Nibu K, Sato N, Iiboshi Y, Yusa K, Kondoh G, Takeda J, Terashima T, Takumi T (2009) Fezf1 is required for penetration of the basal lamina by olfactory axons to promote olfactory development. J Comp Neurol 515:565-584. CrossRef Medline

Wheeler DG, Groth RD, Ma H, Barrett CF, Owen SF, Safa P, Tsien RW (2012) $\mathrm{Ca}(\mathrm{V}) 1$ and $\mathrm{Ca}(\mathrm{V}) 2$ channels engage distinct modes of $\mathrm{Ca}(2+)$ signaling to control CREB-dependent gene expression. Cell 149:1112-1124. CrossRef Medline

Williams T, Courchet J, Viollet B, Brenman JE, Polleux F (2011) AMPactivated protein kinase (AMPK) activity is not required for neuronal development but regulates axogenesis during metabolic stress. Proc Natl Acad Sci U S A 108:5849-5854. CrossRef Medline

Willoughby D, Wachten S, Masada N, Cooper DM (2010) Direct demonstration of discrete $\mathrm{Ca} 2+$ microdomains associated with different isoforms of adenylyl cyclase. J Cell Sci 123:107-117. CrossRef Medline

Wray S (2002) Development of gonadotropin-releasing hormone-1 neurons. Front Neuroendocrinol 23:292-316. CrossRef Medline

Wray S (2010) From nose to brain: development of gonadotrophinreleasing hormone-1 neurones. J Neuroendocrinol 22:743-753. CrossRef Medline

Yuan XB, Jin M, Xu X, Song YQ, Wu CP, Poo MM, Duan S (2003) Signalling and crosstalk of Rho GTPases in mediating axon guidance. Nat Cell Biol 5:38-45. CrossRef Medline

Zhang C, Roepke TA, Kelly MJ, Rønnekleiv OK (2008) Kisspeptin depolarizes gonadotropin-releasing hormone neurons through activation of TRPC-like cationic channels. J Neurosci 28:4423-4434. CrossRef Medline 